\title{
Review Article \\ HIV-1 Tropism Test Evaluation: Assessment and Clinical Implications
}

\author{
Stefania Chiappetta, Manuela Pogliaghi, Marco Ripa, Adriano Lazzarin, \\ Giuseppe Tambussi, and Silvia Nozza \\ Department of Infectious Diseases, San Raffaele Scientific Institute, Via Stamira d'Ancona 20, 20127 Milan, Italy \\ Correspondence should be addressed to Silvia Nozza; silvia.nozza@hsr.it
}

Received 28 February 2014; Accepted 23 March 2014; Published 7 April 2014

Academic Editors: M. Magnani and F. Pulido

Copyright @ 2014 Stefania Chiappetta et al. This is an open access article distributed under the Creative Commons Attribution License, which permits unrestricted use, distribution, and reproduction in any medium, provided the original work is properly cited.

CCR5 and CXCR4 chemokines receptors are critical coreceptors for the binding of HIV to specific host cells. Guidelines recommend its assessment in case of virological failure or before prescription of CCR5 inhibitors. Strategies to assess viral tropism may be divided into phenotypic and genotypic assays; registrative trials of CCR5 inhibitors used phenotypic assay, but recently genotypic ones have been used in clinical practice. The presence of CXCR4 is increasing in naïve patients, with both acute and chronic HIV-1 infections; this coreceptor usage is associated with CD4 depletion. The assessment of viral tropism should be considered in every stage of HIV-1 infection.

\section{Introduction}

HIV enters target cells by interacting with specific surface receptors. While CD4 represents the main molecule with which the HIV envelope is able to interact, several cofactors have been identified. Among those, CCR5 (as discussed by Alkhatib et al. [1]) and CXCR4 (as discussed by Feng et al. [2]) chemokines receptors are critical coreceptors for the binding of HIV to specific host cells. Most HIV-1 quasispecies infect cells expressing CCR5 and are thus defined as CCR5or R5-tropic, while a smaller proportion of viruses bind to CXCR4 and are defined as CXCR4- or X4-tropic. Moreover, some patients harbour mixed viral populations, and some quasispecies are able to use both coreceptors: those patients are defined as carrying dual/mixed viruses (DM-tropic) (as discussed by Berger et al. [3]).

Maraviroc, a CCR5 inhibitor, is the only antiretroviral agent targeting coreceptor binding currently licensed for use in HIV infection. Its use is limited to patients with a determined CCR5 tropism (as discussed elsewhere $[4,5]$ ). Several techniques were developed to assess HIV tropism, and treatment guidelines from different countries are not uniform in defining which methods should be employed in clinical practice.

\section{Methods}

Strategies to assess viral tropism may be divided into two broad categories: phenotypic and genotypic assays. Phenotypic assays determine HIV tropism by culturing host infected cells or by engineering a recombinant virus derived from the virus population of the subject (as discussed by Raymond et al. [6]). Genotypic tests are based on amplification and subsequent sequence analysis of HIV V3 segment by means of prespecified algorithms (as discussed by Obermeier et al. [7]).

Among phenotypic assays, Trofile test has been the most widely used (as discussed by Whitcomb et al. [8]), and it has been recently replaced by an equivalent with enhanced sensitivity (Trofile ES or ESTA) (as discussed by Trinh et al. [9]). This strategy utilizes patient-derived env gene amplified by PCR and inserted into an expression vector. The vector is then cotransfected with a replication-defective proviral vector containing a luciferase reporter gene to give rise to a pseudovirus, which is subsequently used to infect cells expressing CCR5 or CXCR4. To increase sensitivity and specificity of this test, CCR5 and CXCR4 inhibitors are added to test the susceptibility of the virus to these molecules. This test requires a plasma HIV-RNA of more than $1000 \mathrm{cps} / \mathrm{mL}$ 
and has recently been improved, being currently able to detect with $100 \%$ sensitivity CXCR4-tropic clones representing $0.3 \%$ or more of the viral population.

Genotypic assays are based on amplification sequencing of env gene, from both viral RNA and DNA. The sequence obtained is analyzed by a bioinformatic tool which applies an algorithm in order to determine HIV tropism. Several algorithms are currently available, the most widely used being Geno2Pheno (as discussed by Lengauer et al. [10]). This algorithm uses nucleotide sequences compared to a set of sequences corresponding to R5-, DM-, or X4-tropic viruses. The result is given as false positive rate (FPR), that is, the probability of classifying an R5 virus falsely as an X4.

\section{Guidelines}

American Guidelines for the Use of Antiretroviral Agents in HIV-1-Infected Adults and Adolescents (2013) (as discussed elsewhere [11]) recommend the use of tropism testing whenever a CCR5 inhibitor is considered for use (AI) or in case of virologic failure in patients treated with CCR5 inhibitor (BIII). European guidelines on the clinical management of HIV-1 tropism testing (as discussed by Vandekerckhove et al. [12]) suggest the assessment of viral tropism in case of virological failure or poor tolerability to current treatment if a CCR5 inhibitor is considered (AII); moreover, tropism testing is suggested in patients with virological failure or with HAART-related side-effects to give optional insight into future therapeutic choices (BII and CIII, resp.). Finally, European guidelines recommend tropism testing before starting treatment in naïve patients in whom toxicity to first-line treatment is expected (CIII), while testing in newly diagnosed patients currently has no recommendation due to insufficient data.

American guidelines differ from European guidelines in recommending a phenotypic tropism test (AI), considering a genotypic assay as an alternative (BII). European guidelines suggest the use of either phenotypic or genotypic test (BII) when plasma viremia is over $1000 \mathrm{cps} / \mathrm{mL}$, while in patients with a plasma HIV-RNA under $1000 \mathrm{cps} / \mathrm{mL}$ genotypic test on viral RNA (CIII) or DNA (especially if under $50 \mathrm{cps} / \mathrm{mL}$, CIII) is recommended. Values of Geno2Pheno false positive rate under which a virus should be considered X4-tropic are to be set at $10 \%$ after triplicate PCR amplification and sequencing in patients with $>1000 \mathrm{cps} / \mathrm{mL}$ (CII) or $<1000 \mathrm{cps} / \mathrm{mL}$ (BIII) and at $20 \%$ when only one sequence is generated (BIII); FPR threshold of $10 \%$ should also be employed when HIV-DNA is used after triplicate PCR and sequencing (BIII).

\section{Acute Patients}

Reports on determination of coreceptor usage are also studied during primary HIV-1 infection (PHI, defined according to Fiebig staging) and early HIV-1 infection (defined as diagnosed within 6 months of the presumed infection date).

During viral transmission, there is a bottleneck selection by which viral variants using CCR 5 as coreceptor are strongly selected (as discussed by Zhu et al. [13]).
Gottlieb studies HIV-1 envelope genes among 38 patients at a very early stage of infection, before seroconversion. He reports that at least $46 \%$ of patients had replicating virus derived from a single viral variant; moreover, nearly all variants are predicted to be $\mathrm{R} 5$ viruses.

In their recent paper, Hedskog et al. [14] assess whether $\mathrm{X} 4$-tropic viruses are already present during viral transmission by ultradeep pyrosequencing (UDPS) of the V3 loop. He demonstrates that patients diagnosed during $\mathrm{PHI}$ as infected by $\mathrm{R} 5$-tropic viruses who switch over time to $\mathrm{X} 4$ viruses do not have any minor variant using $\mathrm{X} 4$ at the onset of infection. Indeed, the switch from R5 to X4 over time seems to be a viral evolution process from a unique variant.

Although R5 viruses (irrespective of the assay used) are the most frequent type found among early infected patients (as discussed elsewhere $[13,15])$, there is multiple evidence of transmission of CXCR4-tropic viruses.

The evidence that $\mathrm{X} 4$ viruses can be transmitted has emerged during the last few years thanks to the use of either genotypic assays or the Trofile assay (OTA, Monogram), which is a recombinant phenotypic method aimed at assessing on lymphocytes the coreceptor used by the virus. The currently used genotypic test Geno2Pheno could slightly overestimate the frequency of $\mathrm{X} 4$ viruses.

As well described in the review of Verhofstede et al. [16] the prevalence of $\mathrm{X} 4$ or dual mixed tropic (DM) viruses among different cohorts of recent infection varies from $2 \%$ to $19 \%$ (as discussed elsewhere [17-22]).

In terms of clinical outcome, several works confirmed the worst clinical outcome of patients with X4 viruses.

Firstly, X4 viruses transmission seems not to be associated with transmission of drug resistance, as reported by de Mendoza et al. [21].

In a cohort of PHI patients, Chalmet et al. [23] reported that patients infected by $\mathrm{X} 4$ viruses had lower CD4 T cell counts, but no association with viral load was found.

Raymond et al. [24] found that X4 viruses in PHI patients were not associated with CD4 count and viral load, but these patients had a faster decline of CD4 T cells.

Hamlyn et al. [25] measured T cell activation in 120 PHI patients and reported that patients with $\mathrm{X} 4$ viruses had a higher level of immune-activation.

Conversely, Nozza et al. [26] reported that PHI patients with X4 viruses treated with cART had a better CD4 increase over time in comparison to patients carrying R5 viruses.

These contrasting results could be interpreted as the confirmation that X4 viruses are responsible for an accelerated disease progression but that early cART can restore the impairment to the immune-system, not precluding a good clinical outcome.

Anyway, the clinical impact of acquiring an $\mathrm{X} 4$ virus has to be further investigated.

\section{Naive Patients}

The average of CCR5 viruses in naïve HIV-infected patients (pts) changes according to HIV history. In advanced naïve HIV-infected patients with low CD 4 cell count about $40 \%$ of 
patients are non-R5 (as discussed by Charpentier et al. [27]), while in HIV patients with CD4 >350 cells around 14\% are non-R5 (as discussed elsewhere [28]).

Several studies correlate the usage of coreceptor to the immunovirological progression (as discussed by Moyle et al. [29]), suggesting an earlier beginning of ART in X4 HIV virus, but the impact of the CCR5 coreceptor usage on the clinical outcome after the beginning of therapy is not so clear.

Some studies as MERIT and ANRS 130 APOLLO do not show any correlation between HIV coreceptor usage and immunovirological profile. In MERIT (as discussed by McGovern et al. [30]) retrospective study, CCR5 patients have a better immunological response in maraviroc arm of treatment, while no other differences were found among arms. In ANRS 130 APOLLO study (as discussed elsewhere [27]) advance naïve patients were randomized to receive first ART regimen intensification with enfuvirtide or not. At week 24, there are no differences between patients with CCR5 or CXCR4 coreceptor neither in CD4 cell count nor in viraemia. Patients with stable R5 tropism during 24 weeks (34\% of patients) display a better response to ART (tropism measured as Geno2Pheno on HIV-RNA and HIV-DNA).

While in some Italian studies HIV coreceptor usage is associated with a worse CD4 cell count trend before ART initiation, Santoro et al.s study [31] analyses the relationship between HIV-1 coreceptor and immunovirologic parameter both in naïve and experienced patients. Decrease of CD4 cells was higher in patients harbouring $\mathrm{X} 4$ virus than $\mathrm{R} 5$ virus. This correlation is much more evident if FPR is set at $2 \%$ instead of $10 \%$. No correlation is found between coreceptor usage and viraemia. Similar results are found in one Italian cohort (as discussed by Nozza et al. [28]) of 223 primary and chronic HIV-infected patients naïve to ART with CD4 count $\geq 350$ cells $/ \mathrm{mL}$ and HIV-RNA $>500$ copies $/ \mathrm{mL}$ enrolled in the ICONA Foundation. In this cohort, non-R5 viral tropism at $\mathrm{BL}$, determined by Geno2Pheno (FPR $<10 \%$ ), is associated with an increased depletion of CD4 cells count at multivariable analysis during follow-up.

In ArTEn study (as discussed by Seclén et al. [32]) the X4 correlates both with a more rapid decrease of CD4 and higher viraemia at baseline and with a poor response to ART in terms of viral load at w48. In the multivariate analysis CCR5 coreceptor usage is the independent predictor of virologic control during ART, while no significant relationship is found with CD4 cells count. No correlation with ART regimen is found. Similar results are described by Moyle in 2005 (as discussed by Moyle et al. [29]).

Finally Waters et al. [33] do not find any correlation between coreceptor usage and viral load, but there is a direct correlation with the occurrence of AIDS-defining events: $\mathrm{X} 4$ or dual mix HIV predicts a lower increase of CD4 at month 12 after adjustment for baseline characteristics, and the multivariate analysis shows augmented risk of adverse events (RR 2.56).

Once again the clinical impact of $\mathrm{X} 4$ virus is not clear and needs further investigation.

\section{Experienced Patients}

X4 HIV coreceptor usage has significant clinical implications, because it has been associated with higher viral load and lower CD4 T cell count (as discussed by Moyle et al. [29]). These viruses appear to emerge later in progression of HIV disease (as discussed by Berger et al. [34]) and several studies have demonstrated a higher prevalence of $\mathrm{X} 4$ variants in patients exposed to antiretroviral drugs than in drug-naïve individuals (as discussed by Johnston et al. [35] and Delobel et al. [36]).

The presence of $\mathrm{X} 4$ virus is associated with AIDS. As discussed by Delobel et al. [37], in a nonrandomised selection of individuals, approximately two-thirds of the men who develop AIDS have X4-tropic virus. Men who develop X4 viruses have a significant acceleration in the decline of $\mathrm{CD}^{+}$ T lymphocytes, which starts approximately one year after the first appearance of these viruses. These data are consistent with a causal relationship between emergence of non-R5 virus and onset of decreases in the T cell count.

Clinical relevance of tropism testing increases with introduction of CCR5 inhibitors as an antiretroviral treatment option. The MOTIVATE-1 and - 2 studies compare maraviroc along with optimized background therapy (OBT) versus placebo along with OBT in treatment-experienced patients screened as having R5 HIV determined originally by Monogram Trofile (as discussed by Gulick et al. [4]). A retrospective analysis examines the performance of Geno2Pheno to predict coreceptor usage (as discussed by McGovern et al. [38]). Compared with Trofile, V3 genotyping has a specificity of $92.6 \%$ and a sensitivity of $67.4 \%$ for detecting non-R5 virus and virological responses are similar in considered treatmentexperienced population.

There are few data from longitudinal studies on viral tropism in patients fully responding to HAART; as discussed by Parisi et al. [39] there is a correlation between viral tropism and combined HIV-proviral-DNA, residual viraemia, and drugs used in treatment. The tropism of archived virus was stable during the effective treatment, with $15-18 \%$ of subjects switching over time, despite a viraemia $<50$ copies $/ \mathrm{mL}$. R5 tropism and its stability are related to achieving and maintaining viraemia $<2.5$ copies $/ \mathrm{mL}$. A higher stability of viral tropism (88\%) during ARV was reported in a small cohort by Seclén et al. [40], with $12 \%$ switching in either direction. From a clinical point of view, the performance of tropism test on HIV-DNA is suggested before prescription of maraviroc in this setting.

\section{Closing Remarks}

Current guidelines recommend the performance of tropism test in experienced patients, in particular for evaluating therapy with CCR5 inhibitors.

Different studies demonstrated that the presence of X4tropic virus is associated with CD4 decrease and clinical progression; the percentage of this coreceptor usage is different in the clinical setting, as summarized in Table 1.

In addition, viral tropism is changeable in every patient. 
TABLE 1: Percentage of CCR5 tropic virus in different stages of HIV-1 infection.

\begin{tabular}{|c|c|c|c|}
\hline Authors, journal, year of publication & Methods & $\begin{array}{l}\text { Percentage of } \\
\text { patients with } \\
\text { CCR5 tropic virus } \\
\text { (median) }\end{array}$ & $\begin{array}{l}\text { Total number of } \\
\text { patients }\end{array}$ \\
\hline \multicolumn{4}{|c|}{ Acute and early HIV infection } \\
\hline Eshleman et al. [17], AIDS Res Hum Retroviruses 2007 & $\begin{array}{l}\text { Phenotypic (replication-defective } \\
\text { retroviral vector assay) }\end{array}$ & 98 & 195 \\
\hline Huang et al. [18], AIDS Res Hum Retroviruses 2009 & Trofile & 96 & 150 \\
\hline Frange et al. [19], J. Clin. Microbiol. 2010 & $\begin{array}{l}\text { Geno2Pheno }_{\text {FPR } 10 \%} \\
\text { Phenotypic (recombinant virus } \\
\text { entry assay) }\end{array}$ & $88 \%$ & 131 \\
\hline Frange et al. [20], J. Antimicrob. Chemother. 2009 & $\begin{array}{l}\text { Genotypic ( } 5 \text { genotypic rules to } \\
\text { predict tropism) }\end{array}$ & $84 \%$ & 390 \\
\hline De Mendoza et al. [21], J. Antimicrob. Chemother. 2007 & $\begin{array}{l}\text { Genotypic (wetcat prediction } \\
\text { algorithm) }\end{array}$ & $83 \%$ & 203 \\
\hline Rieder et al. [22], Clin. Infect. Dis. 2011 & $\begin{array}{l}\text { Genotypic with } 3 \text { prediction tools } \\
\text { (web-PSSM, wetcat, Geno2Pheno) } \\
\text { Phenotypic (MT2 and GHOST cell } \\
\text { culture assays) }\end{array}$ & $90 \%, 81 \%, 86 \%$ & 145 \\
\hline Chalmet et al. [23], J. Infect. Dis. 2012 & Geno2Pheno & $81-88 \%$ & 539 \\
\hline \multirow[t]{2}{*}{ Raymond et al. [24], AIDS 2010} & $\begin{array}{l}\text { Recombinant virus phenotypic } \\
\text { entry assay (Toulouse tropism test } \\
\text { assay) }\end{array}$ & $93.6 \%$ & \multirow[t]{2}{*}{133} \\
\hline & Geno2Pheno & $88 \%$ & \\
\hline Hamlyn et al. [25], AIDS 2012 & Geno2Pheno $_{\text {FPR } 5.75 \%}$ & $91.7 \%$ & 120 \\
\hline \multirow[t]{3}{*}{ Nozza et al. [26], J. Acquir. Immune Defic. Syndr. 2014} & $\begin{array}{l}\text { Geno2Pheno } \\
\text { PBPR } 10 \% \text { plasma, }\end{array}$ & $87.3 \%$ & \multirow{3}{*}{66} \\
\hline & PSSMx $4 r 5$ & $87 \%$ & \\
\hline & (ds) kernel & $92.4 \%$ & \\
\hline \multirow{2}{*}{ Charpentier et al. [27], J. Antimicrob. Chemother. 2013} & Geno2Pheno $_{\text {FPR } 10 \%}$ on HIV RNA & $60 \%$ & \multirow{2}{*}{170} \\
\hline & Geno2Pheno $_{\mathrm{FPR} 10 \%}$ on HIV DNA & $54 \%$ & \\
\hline Nozza et al. [28], J. Antimicrob. Chemother. 2012 & Geno2Pheno $_{\text {FPR } 10 \%}$ & $86 \%$ & 223 \\
\hline Simon et al. [42], AIDS 2010 & Geno2Pheno $_{\mathrm{FPR} 20 \%}$ & $62 \%$ & 50 \\
\hline Moyle et al. [29], J. Infect. Dis. 2005 & ViroLogic PhenoSense assay & $81 \%$ & 402 \\
\hline \multirow{2}{*}{ Santoro et al. [31], Clin. Microbiol. Infect 2012} & Geno2Pheno $_{\text {FPR } 2 \%}$ & $4.9 \%$ & \multirow{2}{*}{532} \\
\hline & Geno2Pheno $_{\text {FPR } 10 \%}$ & $25 \%$ & \\
\hline \multicolumn{4}{|c|}{ Experienced HIV patients } \\
\hline Gulick et al. [4], N Engl J Med 2008 & Trofile & $70 \%$ & 1049 \\
\hline Caseiro et al. [43], J. Infect. 2012 & Trofile & $84 \%$ & 857 \\
\hline \multirow{2}{*}{$\begin{array}{l}\text { Recordon-Pinson et al. [44], Antimicrob. Agents } \\
\text { Chemother. } 2010\end{array}$} & Trofile & $71.4 \%$ & \multirow{2}{*}{236} \\
\hline & Geno2Pheno $_{\text {FPR10\% }}$ & $77 \%$ & \\
\hline \multirow{2}{*}{ Svicher et al. [45], New Microbiol. 2010} & Trofile & $76.5 \%$ & \multirow{2}{*}{406} \\
\hline & Geno2Pheno $_{\text {FPR10\% }}$ & $70 \%$ & \\
\hline
\end{tabular}

In naïve patients, the presence of $\mathrm{X} 4$-tropic virus is associated with CD4 depletion; its determination in this setting could be useful to individualize a fragile HIV-positive population who could have benefice by early starting of ART.

In successfully treated naive subjects, the tropism of archived virus was revealed to be stable but with a substantial rate (15-18\%) of subjects switching from one type to the other over time, suggesting that archived virus is dynamic.
As discussed by Paquet et al. [41], the fraction of non-R5 tropic viruses has decreased over time within 62,397 resistant viruses reported from 2003 to 2012; however, CXCR4 usage was more prevalent among multiclass resistant samples, which may be due to the more advanced disease stage of treatment-experienced patients.

In conclusion, determination of viral tropism could be useful in the prescription of CCR 5 inhibitors and for better 
knowledge of HIV-positive patients and their prognosis in terms of CD4 depletion.

\section{Conflict of Interests}

The authors declare that they have no conflict of interests.

\section{Acknowledgments}

Giuseppe Tambussi received a grant from ViiV and payment for lectures from MSD and Gilead. Adriano Lazzarin board membership for BMS, ViiV, Abbvie, Gilead, and MSD; Adriano Lazzarin received grants from ViiV, MSD, and BMS and payment for lectures from ViiV, BMS, Gilead, and MSD. Silvia Nozza received travel support, grants, and consultancy from Abbott, BMS, Gilead Sciences, ViiV Healthcare, MSD, and Tibotec (Johnson \& Johnson).

\section{References}

[1] G. Alkhatib, C. Combadiere, C. C. Broder et al., "CC CKR5: a RANTES, MIP- $1 \alpha$, MIP- $1 \beta$ receptor as a fusion cofactor for macrophage-tropic HIV-1," Science, vol. 272, no. 5270, pp. 19551958, 1996.

[2] Y. Feng, C. C. Broder, P. E. Kennedy, and E. A. Berger, "HIV-1 entry cofactor: functional cDNA cloning of a seventransmembrane, G protein-coupled receptor," Science, vol. 272, no. 5263 , pp. $872-877,1996$.

[3] E. A. Berger, R. W. Doms, E.-M. Fenyö et al., "A new classification for HIV-1," Nature, vol. 391, no. 6664, p. 240, 1998.

[4] R. M. Gulick, J. Lalezari, J. Goodrich et al., "Maraviroc for previously treated patients with R5 HIV-1 infection," The New England Journal of Medicine, vol. 359, no. 14, pp. 1429-1441, 2008.

[5] D. A. Cooper, J. Heera, J. Goodrich et al., "Maraviroc versus efavirenz, both in combination with zidovudine-lamivudine, for the treatment of antiretroviral-naive subjects with CCR5tropic HIV-1 infection," Journal of Infectious Diseases, vol. 201, no. 6, pp. 803-813, 2010.

[6] S. Raymond, P. Delobel, and J. Izopet, "Phenotyping methods for determining HIV tropism and applications in clinical settings," Current Opinion in HIV and AIDS, vol. 7, no. 5, pp. 463-469, 2012.

[7] M. Obermeier, J. Symons, and A. M. Wensing, "HIV population genotypic tropism testing and its clinical significance," Current Opinion in HIV and AIDS, vol. 7, no. 5, pp. 470-477, 2012.

[8] J. M. Whitcomb, W. Huang, S. Fransen et al., "Development and characterization of a novel single-cycle recombinant-virus assay to determine human immunodeficiency virus type 1 coreceptor tropism," Antimicrobial Agents and Chemotherapy, vol. 51, no. 2, pp. 566-575, 2007.

[9] L. Trinh, D. Han, W. Huang et al., "Technical validation of an enhanced sensitivity Trofile HIV co-receptor tropism assay for selecting patients for therapy with entry inhibitors targeting CCR5," Antiviral Therapy, vol. 13, supplement 3, p. A128, 2008.

[10] T. Lengauer, O. Sander, S. Sierra, A. Thielen, and R. Kaiser, "Bioinformatics prediction of HIV coreceptor usage," Nature Biotechnology, vol. 25, no. 12, pp. 1407-1410, 2007.

[11] Guidelines for the Use of Antiretroviral Agents in HIV-1-Infected Adults and Adolescents, Department of Health and Human Services, Bethesda, Md, USA, 2007.
[12] L. P. R. Vandekerckhove, A. M. J. Wensing, R. Kaiser et al., "European guidelines on the clinical management of HIV-1 tropism testing," The Lancet Infectious Diseases, vol. 11, no. 5, pp. 394-407, 2011.

[13] T. Zhu, H. Mo, N. Wang et al., "Genotypic and phenotypic characterization of HIV-1 in patients with primary infection," Science, vol. 261, no. 5125, pp. 1179-1181, 1993.

[14] C. Hedskog, J. Brodin, A. Heddini, G. Bratt, J. Albert, and M. Mild, "Longitudinal ultradeep characterization of HIV type 1 $\mathrm{R} 5$ and X4 subpopulations in patients followed from primary infection to coreceptor switch," AIDS Research and Human Retroviruses, vol. 29, no. 9, pp. 1237-1244, 2013.

[15] A. B. van't Wout, N. A. Kootstra, G. A. Mulder-Kampinga et al., "Macrophage-tropic variants initiate human immunodeficiency virus type 1 infection after sexual, parenteral, and vertical transmission," The Journal of Clinical Investigation, vol. 94, no. 5, pp. 2060-2067, 1994.

[16] C. Verhofstede, M. Nijhuis, and L. Vandekerckhove, "Correlation of coreceptor usage and disease progression," Current Opinion in HIV and AIDS, vol. 7, no. 5, pp. 432-439, 2012.

[17] S. H. Eshleman, S. E. Hudelson, R. Bruce et al., "Analysis of HIV type 1 gp41 sequences in diverse HIV type 1 strains," AIDS Research and Human Retroviruses, vol. 23, no. 12, pp. 1593-1598, 2007.

[18] W. Huang, J. Toma, E. Stawiski et al., "Characterization of human immunodeficiency virus type 1 populations containing CXCR4-using variants from recently infected individuals," AIDS Research and Human Retroviruses, vol. 25, no. 8, pp. 795802, 2009.

[19] P. Frange, M.-L. Chaix, S. Raymond et al., "Low frequency of CXCR4-using viruses in patients at the time of primary nonsubtype-B HIV-1 infection," Journal of Clinical Microbiology, vol. 48, no. 10, pp. 3487-3491, 2010.

[20] P. Frange, J. Galimand, C. Goujard et al., "High frequency of $\mathrm{X} 4 / \mathrm{DM}$-tropic viruses in PBMC samples from patients with primary HIV-1 subtype-B infection in 1996-2007: the French ANRS CO06 PRIMO Cohort Study," Journal of Antimicrobial Chemotherapy, vol. 64, no. 1, pp. 135-141, 2009.

[21] C. de Mendoza, C. Rodriguez, F. García et al., "Prevalence of X4 tropic viruses in patients recently infected with HIV-1 and lack of association with transmission of drug resistance," Journal of Antimicrobial Chemotherapy, vol. 59, no. 4, pp. 698-704, 2007.

[22] P. Rieder, B. Joos, A. U. Scherrer et al., "Characterization of human immunodeficiency virus type 1 (HIV-1) diversity and tropism in 145 patients with primary HIV-1 infection," Clinical Infectious Diseases, vol. 53, no. 12, pp. 1271-1279, 2011.

[23] K. Chalmet, K. Dauwe, L. Foquet et al., "Presence of CXCR4Using HIV-1 in patients with recently diagnosed infection: correlates and evidence for transmission," Journal of Infectious Diseases, vol. 205, no. 2, pp. 174-184, 2012.

[24] S. Raymond, P. Delobel, M. Mavigner et al., "CXCR4-using viruses in plasma and peripheral blood mononuclear cells during primary HIV-1 infection and impact on disease progression," AIDS, vol. 24, no. 15, pp. 2305-2312, 2010.

[25] E. Hamlyn, S. Hickling, K. Porter et al., "Increased levels of CD4 T-cell activation in individuals with CXCR4 using viruses in primary HIV-1 infection," AIDS, vol. 26, no. 7, pp. 887-890, 2012.

[26] S. Nozza, A. R. Pignataro, L. Galli et al., "Immunological recovery after 24 weeks of antiretroviral therapy in patients with $\mathrm{X} 4$ virus during primary HIV infection," Journal of Acquired Immune Deficiency Syndromes, vol. 65, no. 1, pp. e27-e29, 2014. 
[27] C. Charpentier, V. Joly, L. Larrouy et al., "Role and evolution of viral tropism in patients with advanced HIV disease receiving intensified initial regimen in the ANRS 130 APOLLO trial," The Journal of Antimicrobial Chemotherapy, vol. 68, no. 3, pp. 690696, 2013.

[28] S. Nozza, F. Canducci, L. Galli et al., "Viral tropism by geno2pheno as a tool for predicting CD4 decrease in HIV1-infected naive patients with high CD4 counts," Journal of Antimicrobial Chemotherapy, vol. 67, no. 5, pp. 1224-1227, 2012.

[29] G. J. Moyle, A. Wildfire, S. Mandalia et al., "Epidemiology and predictive factors for chemokine receptor use in HIV-1 infection," Journal of Infectious Diseases, vol. 191, no. 6, pp. 866872, 2005.

[30] R. A. McGovern, A. Thielen, S. Portsmouth et al., "Populationbased sequencing of the V3-loop can predict the virological response to maraviroc in treatment-naive patients of the MERIT trial," Journal of Acquired Immune Deficiency Syndromes, vol. 61, no. 3, pp. 279-286, 2012.

[31] M. M. Santoro, D. Armenia, L. Fabeni et al., "The lowest X4 Geno2Pheno false-positive rate is associated with greater CD4 depletion in HIV-1 infected patients," Clinical Microbiology and Infection, vol. 18, no. 8, pp. E289-E298, 2012.

[32] E. Seclén, V. Soriano, M. M. González et al., "Impact of baseline HIV-1 tropism on viral response and CD4 cell count gains in HIV-infected patients receiving first-line antiretroviral therapy," Journal of Infectious Diseases, vol. 204, no. 1, pp. 139144, 2011.

[33] L. Waters, S. Mandalia, P. Randell, A. Wildfire, B. Gazzard, and G. Moyle, "The impact of HIV tropism on decreases in CD4 cell count, clinical progression, and subsequent response to a first antiretroviral therapy regimen," Clinical Infectious Diseases, vol. 46, no. 10, pp. 1617-1623, 2008.

[34] E. A. Berger, P. M. Murphy, and J. M. Farber, "Chemokine receptors as HIV-1 coreceptors: roles in viral entry, tropism, and disease," Annual Review of Immunology, vol. 17, pp. 657-700, 1999.

[35] E. R. Johnston, L. S. Zijenah, S. Mutetwa, R. Kantor, C. Kittinunvorakoon, and D. A. Katzenstein, "High frequency of syncytium-inducing and CXCR4-tropic viruses among human immunodeficiency virus type 1 subtype C-infected patients receiving antiretroviral treatment," Journal of Virology, vol. 77, no. 13, pp. 7682-7688, 2003.

[36] P. Delobel, K. Sandres-Sauné, M. Cazabat et al., "R5 to X4 switch of the predominant HIV-1 population in cellular reservoirs during effective highly active antiretroviral therapy," Journal of Acquired Immune Deficiency Syndromes, vol. 38, no. 4, pp. 382392, 2005.

[37] J. C. Shepherd, L. P. Jacobson, W. Qiao et al., "Emergence and persistence of CXCR4-tropic HIV-1 in a population of men from the multicenter AIDS cohort study," Journal of Infectious Diseases, vol. 198, no. 8, pp. 1104-1112, 2008.

[38] R. A. McGovern, A. Thielen, T. Mo et al., "Population-based V3 genotypic tropism assay: a retrospective analysis using screening samples from the A4001029 and MOTIVATE studies," AIDS, vol. 24, no. 16, pp. 2517-2525, 2010.

[39] S. G. Parisi, S. Andreis, G. Palù et al., "A stable CC-chemokine receptor (CCR) -5 tropic virus is correlated with the persistence of HIV RNA at less than 2.5 copies in successfully treated naïve subjects," BMC Infectious Diseases, vol. 13, article 314, 2013.

[40] E. Seclén, M. del Mar González, C. de Mendoza, V. Soriano, and E. Poveda, "Dynamics of HIV tropism under suppressive antiretroviral therapy: implications for tropism testing in subjects with undetectable viraemia," Journal of Antimicrobial Chemotherapy, vol. 65, no. 7, pp. 1493-1496, 2010.

[41] A. C. Paquet, O. D. Solberg, L. A. Napolitano et al., "A decade of HIV-1 drug resistance in the United States: trends and characteristics in a large protease/reverse-transcriptase and coreceptor tropism database from 2003 to 2012," Antiviral Therapy, 2014.

[42] B. Simon, K. Grabmeier-Pfistershammer, A. Rieger, M. Sarcletti, B. Schmied, and E. Puchhammer-Stöckl, "HIV coreceptor tropism in antiretroviral treatment-naive patients newly diagnosed at a late stage of HIV infection," AIDS, vol. 24, no. 13, pp. 2051-2058, 2010.

[43] M. M. Caseiro, M. Nelson, R. S. Diaz et al., "Vicriviroc plus optimized background therapy for treatment-experienced subjects with CCR5 HIV-1 infection: final results of two randomized phase III trials," The Journal of Infection, vol. 65, no. 4, pp. 326335, 2012.

[44] P. Recordon-Pinson, S. Raymond, P. Bellecave et al., "HIV-1 dynamics and coreceptor usage in Maraviroc-treated patients with ongoing replication," Antimicrobial Agents and Chemother$a p y$, vol. 57, no. 2, pp. 930-935, 2013.

[45] V. Svicher, R. D’Arrigo, C. Alteri et al., "Performance of genotypic tropism testing in clinical practice using the enhanced sensitivity version of Trofile as reference assay: results from the OSCAR Study Group," New Microbiologica, vol. 33, no. 3, pp. 195-206, 2010. 

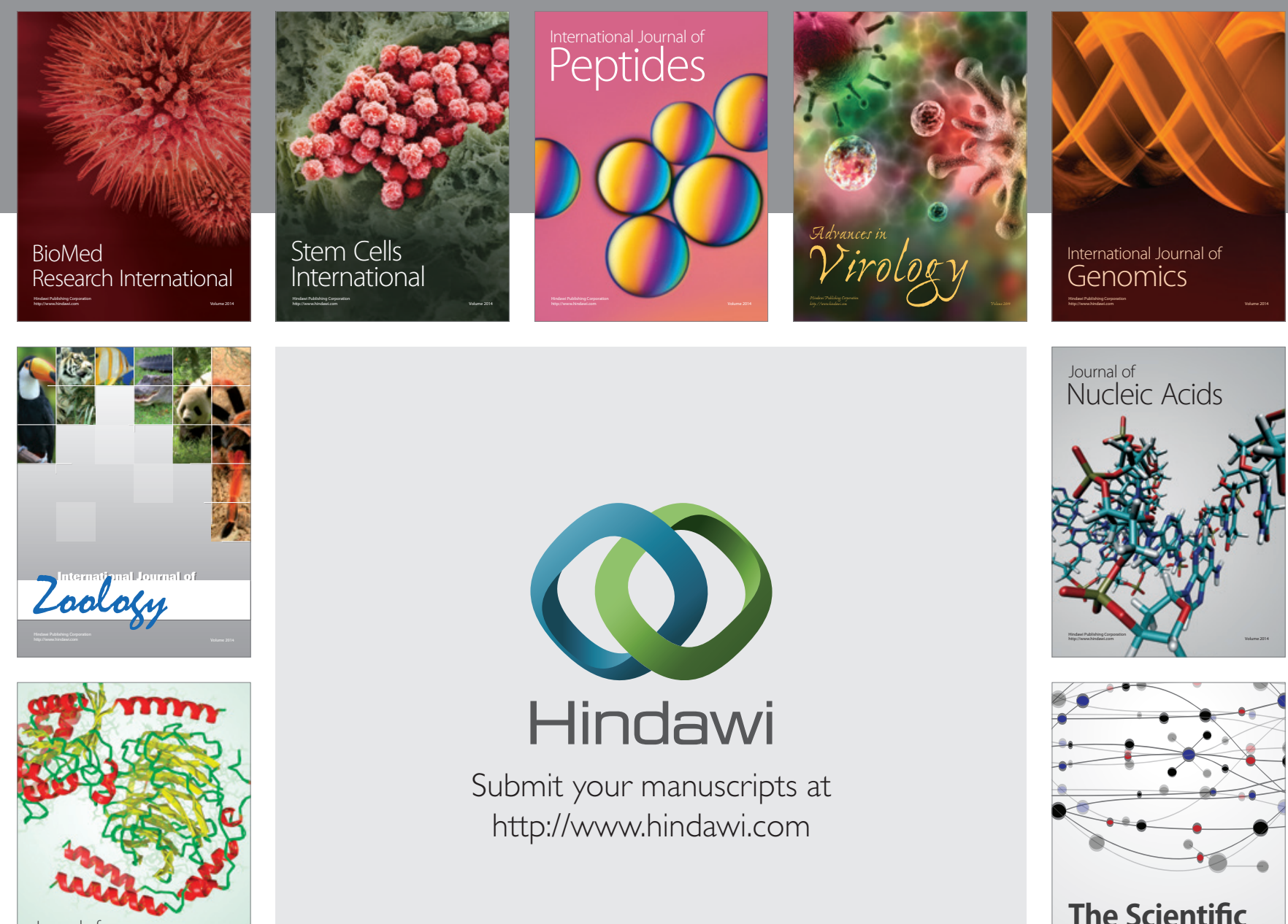

Submit your manuscripts at

http://www.hindawi.com

Journal of
Signal Transduction
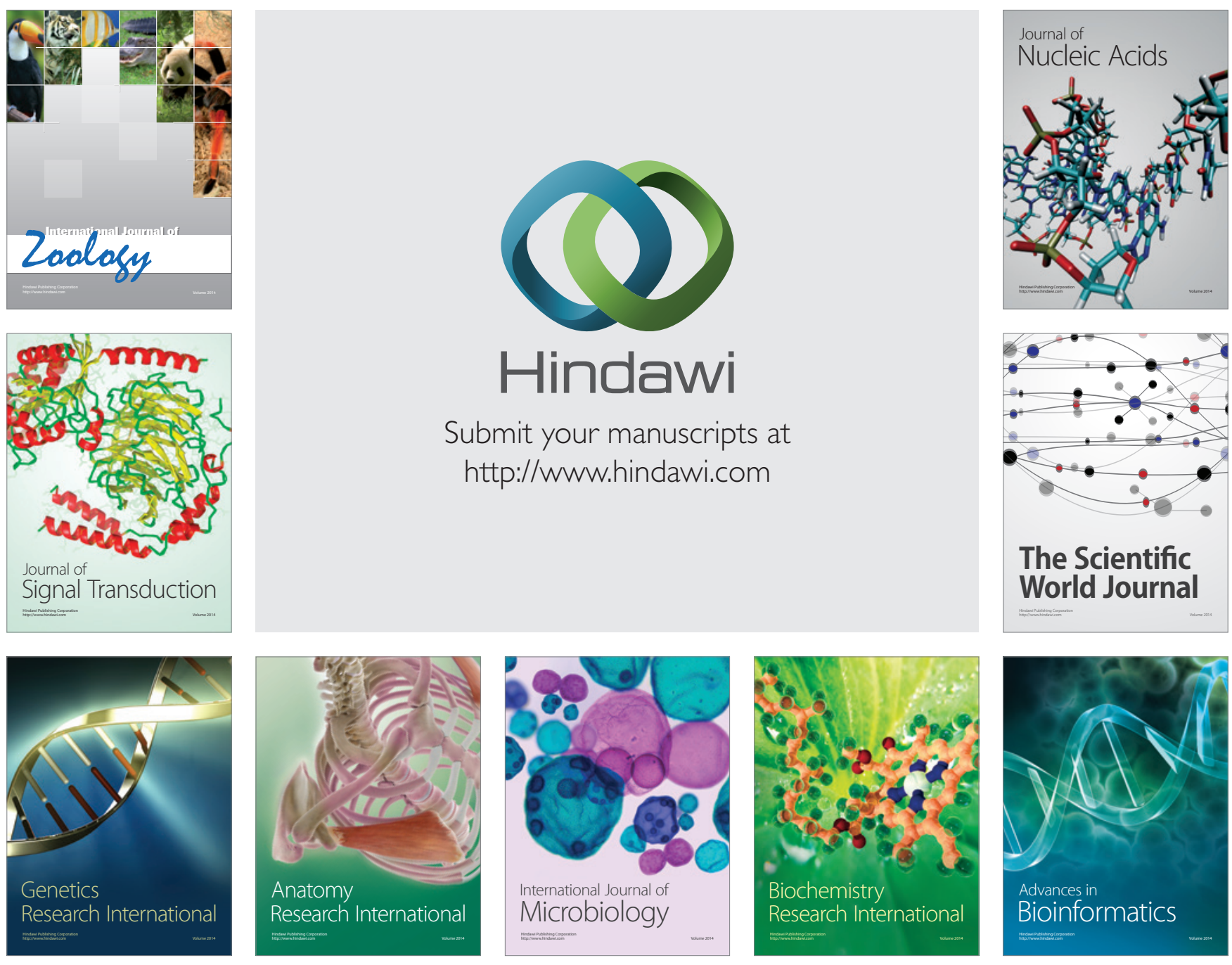

The Scientific World Journal
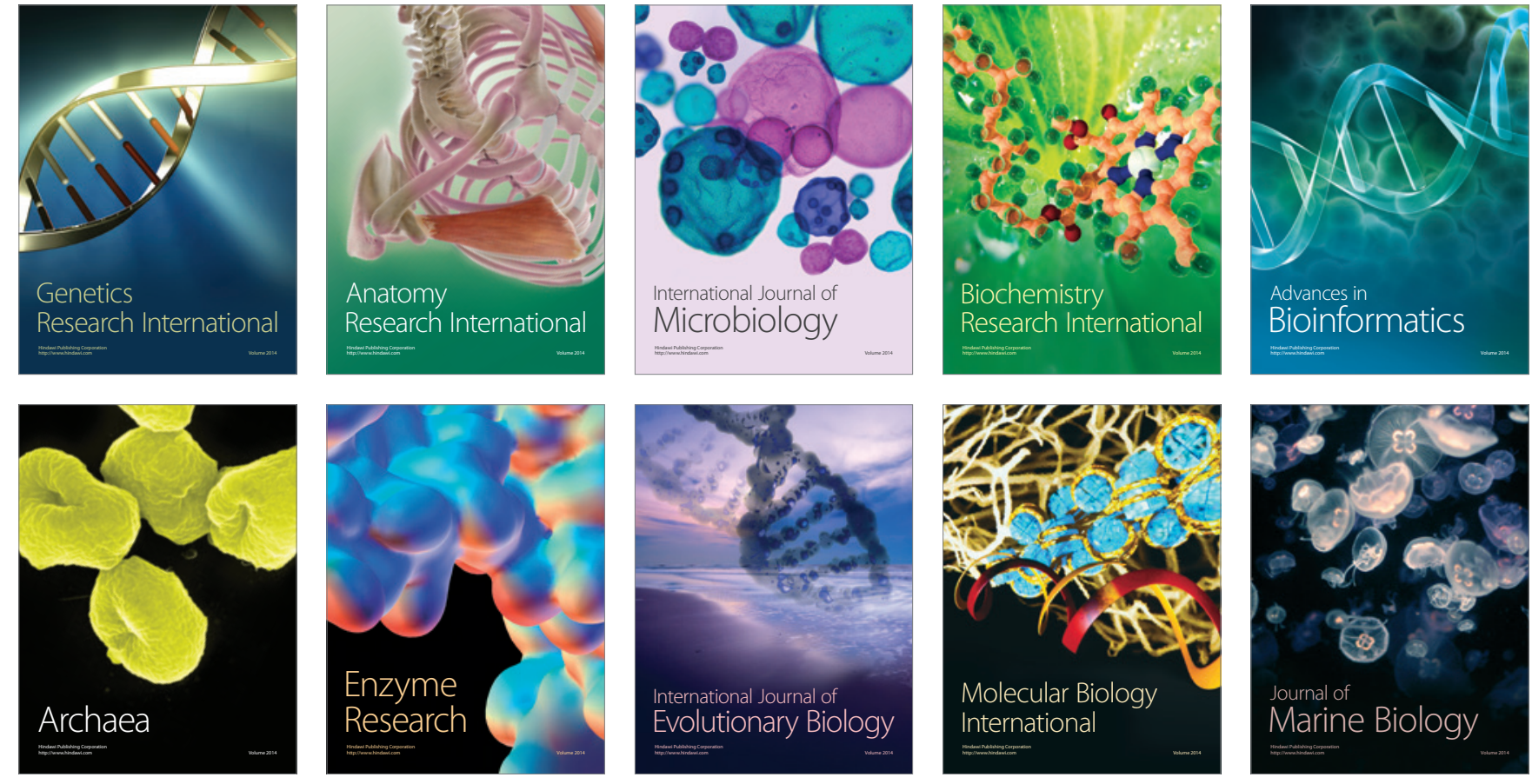